RIBEIRO, Fabiano Colusso; HÜLSE, Levi. Direito colaborativo - um novo olhar sobre a resolução de conflitos. Revista Eletrônica Direito e Política, Programa de Pós-Graduação Stricto Sensu em Ciência Jurídica da UNIVALI, Itajaí, v.13, n.3, 30 quadrimestre de 2018. Disponível em: www.univali.br/direitoepolitica - ISSN 1980-7791

\title{
DIREITO COLABORATIVO - UM NOVO OLHAR SOBRE A RESOLUÇÃO DE CONFLITOS
}

\author{
COLLABORATIVE LAW - A NEW LOOK AT RESOLVING CONFLICTS
}

Fabiano Colusso Ribeiro ${ }^{1}$

Levi Hülse ${ }^{2}$

SUMÁRIO: Introdução; 10 direito colaborativo - visão geral; 2 Os métodos alternativos para resolução de conflitos tradicionais (ADR'S) e sua relação com o direito colaborativo; $3 \mathrm{~A}$ adoção de práticas colaborativas ou direito colaborativo no ordenamento jurídico brasileiro; Considerações finais; Referências das fontes citadas.

\section{RESUMO}

O presente estudo pretende discorrer sobre o Direito Colaborativo, uma nova maneira de praticar o direito através do uso de métodos e técnicas alternativas para a solução de conflitos, cuja aplicação por profissionais do direito em colaboração com as partes e advogados que resulta em tratamento célere e eficaz do conflito, implicando maior satisfação aos envolvidos. $O$ objetivo deste breve estudo é divulgar esta nova prática do direito, como mais uma alternativa à solução de conflitos e que já pode ser utilizada no Brasil.

Palavras-chave: direito colaborativo; jurisdição; poder judiciário; resolução de conflitos; métodos alternativos de resolução de conflitos.

\section{ABCTRACT}

The present study intends to discuss about Collaborative Law, a new way of practicing law through the use of alternative methods and techniques for conflict resolution, whose application by law professionals in collaboration with the parties and lawyers that results in rapid treatment and conflict, implying greater satisfaction to those involved. The purpose of this brief study is to disclose this new law practice, as another alternative to conflict resolution and that can already be used in Brazil. Keywords: Collaborative Law. Jurisdiction. Judicial power. Conflict resolution. Alternative Methods of Conflict Resolution

\footnotetext{
1 Mestre em Ciência Jurídica pela UNIVALI. Especialista em Direito Público pela ESMAFE-RS/UCS (2016), e Direito Aplicado pela Escola Magistratura do Paraná - EMAP (2011). Graduado Bacharel em Direito pela Fundação Universidade Regional de Blumenau FURB (2007). Foi Procurador do Município de Cascavel(PR), e atualmente é Secretário do Juizado Especial e CEJUSC na Comarca de Pomerode (SC).

2 Doutor em Ciência Jurídica pela Universidade do Vale do Itajaí- UNIVALI - SC, na área de concentração em Constitucionalismo, Transnacionalidade e Produção do Direito. Mestre em Ciência Jurídica pela UNIVALI. Graduado Bacharel em Direito pela Fundação Universidade Regional de Blumenau FURB (2010) e graduado em História pela Fundação Universidade Regional de Blumenau FURB (2006). Advogado com a OAB/SC 31.986. Professor na Universidade do Alto Vale do Rio do Peixe - UNIARP. O autor agradece ao Fundo de Apoio à Pesquisa (FAP) da UNIARP pelo apoio financeiro. E-mail: levi@uniarp.edu.br
} 
RIBEIRO, Fabiano Colusso; HÜLSE, Levi. Direito colaborativo - um novo olhar sobre a resolução de conflitos. Revista Eletrônica Direito e Política, Programa de Pós-Graduação Stricto Sensu em Ciência Jurídica da UNIVALI, Itajaí, v.13, n.3, 30 quadrimestre de 2018. Disponível em: www.univali.br/direitoepolitica - ISSN 1980-7791

\section{INTRODUÇÃO}

Neste estudo, dissertamos brevemente sobre o direito colaborativo, um tema originado nos Estados Unidos ${ }^{3}$, onde é intensamente utilizado, mas agora também vem sendo difundido na Europa e atualmente na América Latina ${ }^{4}$. Registre-se que nos países desenvolvidos, o direito colaborativo baseia-se de todo modo nos métodos alternativos de resolução de conflitos tradicionais $\left(A D R^{\prime} s^{5}\right)$, mas também é considerado como uma nova disciplina do Direito, e certamente há possibilidade da aplicação deste método no ambiente legal brasileiro.

Por tal razão desenvolvemos o presente artigo, em três pontos, sendo o primeiro dedicado a análise sobre o que é Direito Colaborativo e suas origens, a fim de esboçar

\footnotetext{
3 A maior expansão do Direito Colaborativo "Collaborative Law" ocorreu principalmente nos Estados Unidos, onde foi inserida como um método específico de resolução de conflitos, contando atualmente a "American Institute of Collaborative Professionals - IACP" com mais de 5.000 membros de 24 países diferentes em todo o mundo. Embora comumente praticado e difundido nos Estados Unidos, a expansão nas últimas décadas pelo no mundo tem sido espetacular em apenas alguns anos de viagem que conduz. Prova disso é que, além dos Estados Unidos, os seguintes países têm profissionais colaborativos: Alemanha, Austrália, Áustria, Bermudas, Canadá, Escócia, Espanha, França, Holanda, Hong Kong, Inglaterra, Irlanda, Israel, Itália, Nigéria, Nova Zelândia e Suíça. Tradução livre pelo autor: Disponível em: <https://www.collaborativepractice.com/public/about/resources-for-the-public/collaborativepractice-groups-around-the-world.aspx>. Acesso em: 15.jan.2018.
}

${ }^{4}$ Devido à extensão desta prática em toda a Europa, o Direito Colaborativo chegou na América Latina. No Brasil, o direito colaborativo, ou denominado "advocacia colaborativa" iniciou-se propriamente em 2011, por meio de três profissionais, sendo uma médica, Tânia Almeida, e duas advogadas, Fernanda Paiva e Flávia Soeiro. Elas, após capacitarem-se nos Estados Unidos resolveram fundar um grupo que envolvem diversos profissionais que estudam tal iniciativa. Apenas a partir de 2012 houve a aplicação das práticas colaborativas em casos reais. Em 2013 o presidente do Supremo Tribunal Federal, Ministro Joaquim Barbosa, reportando-se ao Prêmio Innovare, conquistado por "Práticas Colaborativas no Direito de Família", pelo referido grupo, na categoria Advocacia em 2013, declarou: "é o merecido reconhecimento aos cidadãos e aos profissionais que, no âmbito de suas atividades e de sua comunidade, constroem a Justiça no dia a dia para, assim, sermos uma sociedade mais justa, mais coesa, e provida de mais segurança". Informações extraidas do sítio "Práticas Colaborativas". Disponível em: < http://praticascolaborativas.com.br/home/na-area-de-familia.php\#oque>. Acesso em: 14.jan. 2018.

5 O movimento conhecido como "ADR", a partir dos anos 1980, passou a ser chamado como Alternative Dispute Resolution, conhecido mundialmente por sua sigla ADR, cujas as práticas abrangem os diversos métodos alternativos ao Poder Judiciário, como a arbitragem, conciliação e mediação. O pioneiro nesse tema foi Frank Sander, o qual discorre que o movimento chamado "ADR" não é uma manifestação contra o Poder Judiciário, mas um esforço para que os Tribunais façam efetivamente aquilo que realmente é necessário e de acordo com sua função precípua. Instituições como a arbitragem e mediação devem resolver aqueles casos que não requerem os conhecimentos especializados dos Tribunais. Essa é a ideia por trás do sistema denominado pelo autor como "Tribunal multiportas", ou seja, um centro de Justiça Global, onde os casos são selecionados e analisados, e após a triagem, é indicado o melhor método resolução do conflito de forma eficaz e ágil. SANDER, Frank E. A.. Future of ADR - The Earl F. Nelson Memorial Lecture. Journal of Dispute Resolution. Article 5. Ano 2000. Disponível em: <https://scholarship.law.missouri.edu/jdr/vol2000/iss1/5>. Acesso em: 20.jan.2018, p. 5. 
RIBEIRO, Fabiano Colusso; HÜLSE, Levi. Direito colaborativo - um novo olhar sobre a resolução de conflitos. Revista Eletrônica Direito e Política, Programa de Pós-Graduação Stricto Sensu em Ciência Jurídica da UNIVALI, Itajaí, v.13, n.3, 30 quadrimestre de 2018. Disponível em: www.univali.br/direitoepolitica - ISSN 1980-7791

um panorama geral sobre essa nova e emergente forma de exercer o direito, evitando-se a todo custo a excessiva judicialização de questões civis ou contratuais.

Dentro do segundo ponto, a diferença e os pontos comuns deste método alternativo em relação aos outros, tais como conciliação, mediação e arbitragem, as quais se baseiam as práticas colaborativas no dito direito colaborativo. Por fim, na terceira parte, discorremos sobre sua utilização no Brasil, especialmente sua materialização em eventuais pactos, instrumentos ou contratos, etapa necessária para operacionalizar as práticas colaborativas, de modo que seja demonstrada a viabilidade da proposta feita.

Finalmente, as conclusões e recomendações que vêm de todo o desenvolvimento do assunto, no qual propomos expandir o conhecimento sobre tal maneira de praticar o direito, em verdade, busca a solução de conflitos permitindo-se que o litígio entre as partes seja resolvido amigavelmente com mais compreensão e colaboração por intermédio de profissionais especializados.

O método que foi usado principalmente para a presente investigação foi a pesquisa bibliográfica em que se buscou identificar os trabalhos científicos mais relevantes sobre o tema, com o objetivo de realizar um trabalho com amplitude suficiente para sua utilização como revisão bibliográfica a demonstrar o tema estudado.

\section{O DIREITO COLABORATIVO - VISÃO GERAL}

O Direito colaborativo ou como denominado na origem como "Collaborative Law", nasceu nos Estados Unidos no final dos anos oitenta. Um advogado atuante no direito de família, em Minneapolis, Stuart Webb, depois de exercer a defesa de seus clientes por quase 20 (vinte) anos, começa a se interessar por Métodos Alternativos de Resolução de Conflitos (MASC's ou ADR's), com o objetivo de alcançar uma solução mais adequada às circunstâncias específicas de cada conflito, deixando para trás métodos convencionais e padronizados que, dificilmente, poderiam ser adaptados a cada situação específica. ${ }^{6}$

6 WEBB, Stuart. G. OUSKY, Ronald D.. The collaborative way to divorce: the revolutionary method that results in less stress, lower costs, and happier kids without going to court. Editora Plume, $1^{a}$ ed., Estados Unidos, 2007, p. 15. Ainda neste sentido: IACP - International Academy of Collaborative Professionals. História do Direito Colaborativo. Disponível em: 
RIBEIRO, Fabiano Colusso; HÜLSE, Levi. Direito colaborativo - um novo olhar sobre a resolução de conflitos. Revista Eletrônica Direito e Política, Programa de Pós-Graduação Stricto Sensu em Ciência Jurídica da UNIVALI, Itajaí, v.13, n.3, $3^{\circ}$ quadrimestre de 2018. Disponível em: www.univali.br/direitoepolitica - ISSN 1980-7791

Primeiro, fixou seu foco na mediação; no entanto, propôs buscar um novo método baseado principalmente na negociação, onde intervêm os advogados que defendem os interesses de seus respectivos clientes. Ele alertou seus clientes de que ele os ajudaria a resolver e negociar seus problemas apenas fora dos Tribunais, mas que não iria mais defendê-los judicialmente em seus divórcios, retirando-se do caso, se porventura as partes decidirem recorrer a judicialização da questão, bem como recomendou que seus clientes procurassem outro advogado com comportamento focado em disputas judiciais.

Foi assim que, em 1990, Stuart Webb proclamou-se um "advogado colaborativo", limitando seu desempenho profissional em processos colaborativos, ou seja, uma atuação focada na seara extrajudicial ${ }^{7}$.

Em paralelo, em meados de 1992, na Califórnia, os psicólogos Peggy Thomson e Rodney Nurse começaram a desenvolver uma nova maneira de orientar os casais divorciados, propondo uma maneira muito mais construtiva, dando outra abordagem ao divórcio. Em alguns dias dessa experiência pragmática, decidiram compartilhar suas perspectivas e ideias, desenvolvendo então a prática colaborativa multidisciplinar, com o auxílio de diversos profissionais da área jurídica, saúde e humanas (psicólogos, terapeutas, advogados, etc.) ${ }^{8}$.

No ano de 1999, surge o American Institute of Collaborative Professionals, cuja criação visa promover a colaboração entre profissionais das aludidas áreas com intuito de intercâmbio de suas experiências colaborativas. Dada a expansão desta técnica pelo Canadá e Estados Unidos, em 2001, torna-se a Academia Internacional de Profissionais Colaborativos, atualmente denominada simplesmente "IACP"9.

<https://www.collaborativepractice.com/public/about/about-iacp/history.aspx>. Acesso em: 13.jan.2018.

7 WEBB , Stuart. G. OUSKY, Ronald D., p. 15-16.

${ }^{8}$ IACP - International Academy of Collaborative Professionals. História do Direito Colaborativo. Disponível em: <https://www.collaborativepractice.com/public/about/about-iacp/history.aspx>. Acesso em: 13.jan.2018. Em igual sentido vide: VOEGELE, Gary L.; OUSKY, Ronald D.; and WRAY, Linda K.. Collaborative Law: A Useful Tool for the Family Law Practitioner to Promote Better Outcomes. William Mitchell Law Review, 2007, Vol. 33: Iss. 3, Article 10, Disponível em: <http://open.mitchellhamline.edu/wmlr/vol33/iss3/10>. Acesso em: 22.dez.2017, p. 974-975.

9 IACP - International Academy of Collaborative Professionals. História do Direito Colaborativo. Disponível em: <https://www.collaborativepractice.com/public/about/about-iacp/history.aspx>. Acesso em: 13.jan.2018. 
RIBEIRO, Fabiano Colusso; HÜLSE, Levi. Direito colaborativo - um novo olhar sobre a resolução de conflitos. Revista Eletrônica Direito e Política, Programa de Pós-Graduação Stricto Sensu em Ciência Jurídica da UNIVALI, Itajaí, v.13, n.3, 30 quadrimestre de 2018. Disponível em: www.univali.br/direitoepolitica - ISSN 1980-7791

O sucesso desta associação de profissionais unidos pela prática colaborativa nos Estados Unidos é tal que, em 2009, eles decidiram elaborar um texto normativo que regula todo o processo colaborativo, ou melhor, uma norma padrão. O documento chamado de Uniform Collaborative Law Act (UCLA) foi criado e adotado pela Comissão de Direito Uniforme, tornando-o disponível para cada um dos Estados Americanos para que pudessem implementá-lo como lei local. Em 2010, a UCLA foi modificada e definitivamente transformada na Uniform Collaborative Law Rules and Act (UCLRA). Após o lançamento desta proposta de regulamentação, vários Estados decidiram integrá-la como padrão legislativo ${ }^{10}$.

Assim, o Direito Colaborativo, é uma nova maneira de exercer o direito que permite resolver os problemas sem a necessidade ajuizar um processo judicial ou contencioso. É dizer, ao discorrer sobre esta maneira nova, refere-se na realidade, a um assunto novo que é tema de debate em países europeus e agora latinoamericanos, embora em outros países desenvolvidos como Estados Unidos, Canadá, Austrália ou Inglaterra ${ }^{11}$ é uma disciplina bastante difundida desde da década de 1990, como pode ser visto, o sistema anglo-saxão se vale mais desta forma de exercer o direito e resolver conflitos ${ }^{12}$.

Na prática, cada cliente é assistido por um advogado especializado ou capacitado em práticas colaborativas, cujas competências envolvem o conhecimento de técnicas de comunicação, negociação, utilizando-se por vezes das mesmas técnicas de um procedimento de mediação ou arbitragem. Então, de modo geral, as partes, assistidas por advogados, subscrevem um acordo de participação em que as bases do procedimento são definidas, bem como é firmado compromisso de não litigar

\footnotetext{
10 IACP - International Academy of Collaborative Professionals. História do Direito Colaborativo. Disponível em: <https://www.collaborativepractice.com/public/about/about-iacp/history.aspx>. Acesso em: 13.jan.2018.

11 "Currently, Collaborative Law is practiced in virtually every state and province in the United States and Canada, as well as overseas, particularly in Great Britain and Australia.The exponential growth of Collaborative Law has sparked the interest and curiosity of the academic community around the world". VOEGELE, Gary L.; OUSKY, Ronald D.; and WRAY, Linda K.. Collaborative Law: A Useful Tool for the Family Law Practitioner to Promote Better Outcomes. William Mitchell Law Review: Vol. 33: Iss. 3, Article 10, p. 975.2007 .2 Disponível em: <http://open.mitchellhamline.edu/wmlr/vol33/iss3/10>. Acesso em: 22.dez.2017.

12 ESTEVE, Patricia E. Abogado colaborativo: una nueva forma de resolución de conflictos. Revista Jurídica da Catalunha, RJC, núm. 1-2016, págs. 71-95. Veja também: DENARDI, Eveline Gonçalves; MOURA, Isabel Cristina de; FERNANDES, Mariana Correa. As práticas colaborativas como um recurso para as situações de divórcio. Revista da Faculdade de Direito da UFRGS, Porto Alegre, n. 36, vol. esp., p. 59, out. 2017.
} 
RIBEIRO, Fabiano Colusso; HÜLSE, Levi. Direito colaborativo - um novo olhar sobre a resolução de conflitos. Revista Eletrônica Direito e Política, Programa de Pós-Graduação Stricto Sensu em Ciência Jurídica da UNIVALI, Itajaí, v.13, n.3, 30 quadrimestre de 2018. Disponível em: www.univali.br/direitoepolitica - ISSN 1980-7791

durante o referido procedimento extrajudicial. Todos funcionam assim como uma equipe para resolver dúvidas, descobrir interesses e encontrar soluções criativas para todas as partes ${ }^{13}$.

Segundo um dos seus precursores, Pauline H. Tesler, o direito colaborativo tem como seu elemento central, uma "regra de ouro", no qual os participantes (terceiros), advogados e clientes, comprometem-se que não vão ameaçar ou recorrer à intervenção judicial durante a pendência do procedimento colaborativo e também toda e qualquer informação será compartilhada, divulgada. Todos os esforços deve ocorrem inteiramente fora dos Tribunais. Segundo o referido autor, por essa razão, o modelo revelou-se facilmente adaptável em toda linhas de jurisdição, apesar das significativas diferenças legislativas entre os Estados ${ }^{14}$, característica própria do direito americano ${ }^{15}$.

Por sua vez, Marilyn K. Scott esclarece que ao contrário do contencioso tradicional o direito colaborativo permite que os advogados e seus clientes trabalhem conjuntamente sem um concurso de um Tribunal. Eles vão divulgar todas as informações pertinentes ao conflito, de maneira aberta e honestamente negociar de boa-fé para resolver todas as questões de interesse das partes. Mas a autora adverte

13 ESTEVE, Patricia E. Abogado colaborativo: una nueva forma de resolución de conflictos. Revista Jurídica da Catalunha, RJC, núm. 1-2016, págs. 71-95. Em igual sentido: TESLER, Pauline H.. Collaborative Family Law, Pepperdine Dispute Resolution Law Journal. L.J. Iss. 3, 2004, pp.. 317318. Disponível em: <http://digitalcommons.pepperdine.edu/drlj/vol4/iss3/2>. Acesso em: 12.dez.2018.

14 Sobre o tema de autonomia legislativa dos Estados naquele país confira: "Frisa-se, também, que no federalismo (federalism) dos Estados Unidos existem duas dimensões de governo, a federal (federal) e a estadual (state), caracterizadas pela divisão de poderes dentro de espaços territoriais, com autonomia entre os Estados e soberania garantida à federação. Além do governo federal (federal government), há 50 Estados (States), sendo a todos assegurado um sentido de independência e de poder muito grande"[...] Com 51 governos diferentes (o federal e outros 50 estaduais), sendo cada qual com seu sistema jurídico independente e com amplo poder para definir o direito vigente no seu espaço de competência, assiste razão ao jurista Antonio Gidi ao concluir que há mais segurança jurídica, em termos de definição dos direitos e das suas categorias jurídicas, no sistema brasileiro do que no sistema dos Estados Unidos, onde a segurança jurídica vai se construindo aos poucos, ao longo do tempo, com erros e acertos nas decisões judiciais, até que haja orientação jurisprudencial de caráter mais definitivo". ALMEIDA, Gregório Assagra de. O Sistema Jurídico nos Estados Unidos. Revista de Processo. Editora Revista dos Tribunais. v. 41, n. 251, jan., 2016, p. 523560 .

15 TESLER, Pauline H.. Collaborative Family Law, Pepperdine Dispute Resolution Law Journal. L.J. Iss. 3, 2004, p. 317-318. Disponível em: <http://digitalcommons.pepperdine.edu/drlj/vol4/iss3/2>. Acesso em: 12.dez.2017. 
RIBEIRO, Fabiano Colusso; HÜLSE, Levi. Direito colaborativo - um novo olhar sobre a resolução de conflitos. Revista Eletrônica Direito e Política, Programa de Pós-Graduação Stricto Sensu em Ciência Jurídica da UNIVALI, Itajaí, v.13, n.3, 30 quadrimestre de 2018. Disponível em: www.univali.br/direitoepolitica - ISSN 1980-7791

que não estamos a falar da negociação típica pela qual estamos acostumados nos litígios tradicionais ${ }^{16}$.

Nos dizeres de Scott, o direito colaborativo trabalha com a negociação facilitadora, com abordagem multidisciplinar para a resolução dos conflitos, permitindo-se reconhecer e incorporar o conhecimento de psicólogos, contabilistas, consultores de inúmeras áreas do conhecimento (financeira, administrativa, biológica), ou qualquer outro profissional com experiência necessária para ajudar as partes a elaborar seu próprio acordo, como veremos adiante.

O Estado do Texas, um dos primeiros a dar reconhecimento legislativo aos processos colaborativos, definindo-o legalmente o "Collaborative Law" como:

"[A] procedure in which the parties and their counsel agree in writing to use their best efforts and make a good faith attempt to resolve their dissolution of marriage dispute on an agreed basis without resorting to judicial intervention except to have the court approve the settlement agreement, make the legal pronouncements, and sign the orders required by law to effectuate the agreement of the parties as the court determines appropriate. The parties' counsel may not serve as litigation counsel except to ask the court to approve the settlement agreement." [TEX. FAM. CODE ANN. § 6.603(b) (Vernon Supp. 2004); see also TEx. FAM. CODE ANN. § 153.0072 (Vernon 2002)]. ${ }^{17}$

Por fim uma última definição de Direito Colaborativo, trazida por Marcos Loredo Colunga em seus estudos na Espanha, descreve como um procedimento através do qual as partes, auxiliadas por seus advogados colaborativos e por meio do diálogo entre eles, conseguem chegar a um acordo para resolver seu litígio em reuniões conjuntas, apesar de outros profissionais poderem intervir [intervenção é necessária

\footnotetext{
16 SCOTT, Marilyn. Collaborative Law: Dispute Resolution Competencies for the 'New Advocacy'. QUT Law Review, v. 8, n. 1, june 2008. Disponível em: <https://Ir.law.qut.edu.au/article/view/107>. Acesso em: 23.dez. 2017, p. 214-215.

17 Procedimento em que as partes e seus advogados concordam por escrito para usar seus melhores esforços e boa-fé para resolver sua dissolução do casamento(divórcio) de forma acordada sem recorrer a intervenção judicial, exceto para que o Tribunal homologue o acordo, ou determine alteraçõe exigidas por Lei para homologar o acordo das partes, conforme o Tribunal entender mais adequado. Os advogados das partes não podem servir como consultor jurídico, assessor, procurador, exceto para pedir ao Tribunal a homologação do acordo ou execução dele. [Tradução livre pelo autor]. SPAIN, Larry. Collaborative Law: A Critical Reflection on Whether a Collaborative Orientation Can Be Ethically Incorporated in the Practice of Law. Baylor Law Review, Vol. 56, No. 1, 2004. Disponível em: <https://ssrn.com/abstract=2134397>. Acesso em: 12.jan.2018, p. 142.
} 
RIBEIRO, Fabiano Colusso; HÜLSE, Levi. Direito colaborativo - um novo olhar sobre a resolução de conflitos. Revista Eletrônica Direito e Política, Programa de Pós-Graduação Stricto Sensu em Ciência Jurídica da UNIVALI, Itajaí, v.13, n.3, $3^{\circ}$ quadrimestre de 2018. Disponível em: www.univali.br/direitoepolitica - ISSN 1980-7791

ou aconselhável], tais como a efetiva participação de psicólogos, auditores, terapeutas, mediadores, etc. ${ }^{18}$

A nota mais característica desta prática, segundo o referido estudioso, é a inibição dos profissionais que intervêm no processo colaborativo em relação ao possível litígio subsequente que eventualmente surgir, acaso não cheguem as partes em um acordo. Noutras palavras, se as partes não chegarem ao acordo e decidirem canalizá-lo no Poder Judiciário, os profissionais que intervieram no procedimento colaborativo não poderão continuar a auxiliar as partes no processo judicial ${ }^{19}$.

Uma vez definido seu conceito faz-se necessário trazer os elementos básicos do direito colaborativo, ou melhor suas características essenciais, marcantes em todo procedimento colaborativo. Sandra Crawford elencou como elementos básicos, além do acordo escrito para concentração mútua de esforços para resolução do conflito, o princípio do consentimento informado por todos participantes; compromisso dos profissionais de retirar-se, acaso uma das partes/clientes resolva acionar a intervenção judicial ou ameaça-lo de fazê-lo; voluntariedade, boa-fé e honestidade de todas as partes envolvidas; o compromisso de esforçar-se para que as soluções atendam os interesses de todas as partes ${ }^{20}$.

Por sua vez, Gary L. Voegele, Ronald D. Ousky e Linda K. Wray, em exaustiva análise sobre o direito colaborativo estabeleceram uma característica central e outras comuns. A primeira é a existência de um acordo de desqualificação, melhor definido na origem como "Disqualification Agreement" ou "Withdrawal Provision" e até mesmo "Collaborative Commitment"; já as características comuns são inúmeras, dentre as quais destacam-se reuniões ou sessões conjuntas chamadas "four-way meetings"; negociação baseadas em interesses ou baseadas em princípios (Interest-Based Resolution); princípio da transparência ou descoberta informal (divulgação de todos os fatos do processo); abordagem holística do conflito; controle do procedimento e

18 LOREDO COLUNGA, M.. El método colaborativo: nuevos horizontes en el marco de la autocomposición. Revista de Justicia Restaurativa, Violencia de Género, Justicia Restaurativa y Mediación. Editora Grupo Wolters Kluwer. n.2, 2011, p. 535.

19 LOREDO COLUNGA, M.. El método colaborativo: nuevos horizontes en el marco de la autocomposición. Revista de Justicia Restaurativa, Violencia de Género, Justicia Restaurativa y Mediación. Editora Grupo Wolters Kluwer. n.2, 2011, p. 535.

${ }^{20}$ CRAWFORD, SANDRA. Collaborative Law: A Brief Overview. Illinois Bar Journal; Sep.2017, Vol. 105, Issue 9. Disponível em: < http://collablawil.org/wp-content/uploads/2017/09/CollaborativeOverview.pdf>. Acesso em: 10.jan. 2018, p.29. 28-31. 
RIBEIRO, Fabiano Colusso; HÜLSE, Levi. Direito colaborativo - um novo olhar sobre a resolução de conflitos. Revista Eletrônica Direito e Política, Programa de Pós-Graduação Stricto Sensu em Ciência Jurídica da UNIVALI, Itajaí, v.13, n.3, $3^{\circ}$ quadrimestre de 2018. Disponível em: www.univali.br/direitoepolitica - ISSN 1980-7791

do resultado do processo pelos participantes; geração de opções ao cliente; protocolos de boas práticas ${ }^{21}$. Registra-se nesse ponto, que não é o objetivo deste artigo esmiuçar cada uma das características mas traçar um panorama geral do instituto.

Ainda, fica destacado pelos autores o importantíssimo acordo de desqualificação, como ponto chave do direito colaborativo, pois este pacto é firmado por todos os participantes, cujo texto enuncia que os advogados vão retirar-se do procedimento colaborativo acaso o litígio seja levado para esfera judicial ou exista a ameaça de fazê-lo. ${ }^{22}$

Tal documento, segundo os autores, é imprescindível para caracterizar um caso como colaborativo e uma exclusividade dessa espécie de método de resolução de conflitos. Os profissionais da área que atuam nesse segmento sabem da importância desse documento para o sucesso do método, o que não pode ser uma mera formalidade. Isso porque o instrumento evidencia três aspectos essenciais do direito colaborativo, quais sejam, o compromisso dos participantes com o procedimento e suas regras; segurança jurídica em ambiente fora do Poder Judiciário (ambiente "ganha-ganha"); e o aumento da cooperação das partes (aplicação da teoria dos jogos - dilema do prisioneiro $)^{23}$.

Em síntese, para os juristas Oswin Chrisman, Lori Chrisman e Gay G. Cox, o direito colaborativo se traduz em práticas colaborativas num processo orientado para a solução de conflitos baseados em interesses, o qual tem demonstrado sucesso preeminente na resolução de questões de direito de família. Logicamente, não é exclusivo desta área [onde foi desenvolvido] e oferece muitas vantagens as quais incluem: evita-se o desgaste da batalha judicial mantendo-se o controle do processo e o resultado; geração e criação e soluções pelos participantes, permitindo-se

\footnotetext{
21 VOEGELE, Gary L.; OUSKY, Ronald D.; and WRAY, Linda K.. Collaborative Law: A Useful Tool for the Family Law Practitioner to Promote Better Outcomes. William Mitchell Law Review: Vol. 33: Iss. 3, Article 10. Disponível em: <http://open.mitchellhamline.edu/wmlr/vol33/iss3/10>. Acesso em: 22.dez.2017, 2007, pp. 980-981.
}

22 VOEGELE, Gary L.; OUSKY, Ronald D.; and WRAY, Linda K.. Collaborative Law: A Useful Tool for the Family Law Practitioner to Promote Better Outcomes. p. 980-981.

23 VOEGELE, Gary L.; OUSKY, Ronald D.; and WRAY, Linda K.. Collaborative Law: A Useful Tool for the Family Law Practitioner to Promote Better Outcomes. p. 980-981. 
RIBEIRO, Fabiano Colusso; HÜLSE, Levi. Direito colaborativo - um novo olhar sobre a resolução de conflitos. Revista Eletrônica Direito e Política, Programa de Pós-Graduação Stricto Sensu em Ciência Jurídica da UNIVALI, Itajaí, v.13, n.3, $3^{\circ}$ quadrimestre de 2018. Disponível em: www.univali.br/direitoepolitica - ISSN 1980-7791

fornecer privacidade, flexibilidade e negociações diretas; preserva relacionamentos valiosos; e reduz os custos legais.

Além disso, a prática colaborativa é a única, dentre os demais métodos alternativos de resolução de conflitos (ADR's), que detém a capacidade de fornecer também aos clientes o benefício da advocacia e consultoria jurídica, sem qualquer preocupação com a neutralidade. ${ }^{24}$

Delineado o panorama geral do direito colaborativo, cabe identificar as diferenças e pontos comuns entre outros métodos de resolução de conflitos, mais difundidos em nosso ambiente jurídico, tais como a conciliação, mediação e arbitragem.

\section{OS MÉTOdOS ALTERNATIVOS PARA RESOLUÇÃO DE CONFLITOS TRADICIONAIS (ADR'S) E SUA RELAÇÃO COM O DIREITO COLABORATIVO}

Diante da falta de capacidade dos Tribunais para resolver conflitos advieram inúmeras reformas nas leis processuais, buscando velocidade e eficácia na gestão de conflitos e descongestionamento deles. Os métodos alternativos para a solução de conflitos (ADR's) são hoje, especialmente no Brasil, um quadro legal completo, mas disperso, o que permite a existência de uma justiça efetiva e célere com um conjunto de ferramentas alternativas de resolução de conflitos, mas que ainda são intimamente ligadas ao Poder Judiciário. ${ }^{25}$

Um dos fenômenos mais proeminentes na evolução recente do ordenamento jurídico em países de modernidade tardia, incluído aí o Brasil, são o uso maciço dos chamados métodos alternativos de resolução de conflitos (MASC's ou ADR's). Há vasta literatura sobre eles, e em alguns países os legisladores dedicam um número cada vez maior de padrões destinados a encorajar todas as formas possíveis de usar essas. ${ }^{26}$

Nos últimos anos investiu-se muitos na resolução alternativa de conflitos e na humanização do Poder Judiciário com a adoção de inúmeros métodos para

\footnotetext{
${ }^{24}$ P. Oswin Chrisman, Gay G. Cox, and Petra Novotna, Collaborative Practice Mediation: Are We Ready to Serve this Emerging Market. Pepperdine Dispute Resolution Law Journal n. 6, Iss. 3, 2006, Disponível em: <http://digitalcommons.pepperdine.edu/drlj/vol6/iss3/4>. Acesso em: 22.dez.2017, p. 452.

25 SANTOS, Boaventura de Sousa. Os tribunais nas sociedades contemporâneas. Revista brasileira de ciências sociais. v. 11, n. 30, ps. 29-62, fev. 1996.
}

2626 SANTOS, Boaventura de Sousa. Os tribunais nas sociedades contemporâneas. 
RIBEIRO, Fabiano Colusso; HÜLSE, Levi. Direito colaborativo - um novo olhar sobre a resolução de conflitos. Revista Eletrônica Direito e Política, Programa de Pós-Graduação Stricto Sensu em Ciência Jurídica da UNIVALI, Itajaí, v.13, n.3, $3^{\circ}$ quadrimestre de 2018. Disponível em: www.univali.br/direitoepolitica - ISSN 1980-7791

desjudicialização dos litígios. Isso porque, a letargia dos Tribunais é reflexo de "um sistema social muito injusto e muito iníquo que deixa os cidadãos mais vulneráveis, pretensamente autônomos, a mercê de violências, extremismos e arbitrariedades por parte de agentes econômicos e sociais muito poderosos". ${ }^{27}$

Nesse senda, Boaventura de Sousa Santos, propõe "uma revolução democrática da justiça", a qual prevê uma agenda que coincide com práticas sustentáveis de inclusão social, reforçando ou facilitando o acesso aos direitos pela população mais fragilizada. ${ }^{28}$

Para Santos é preciso despertar uma transformação no acesso a justiça, de cunho jurídico-político, observando-se os seguintes vetores:

- Profundas reformas processuais; - Novos mecanismos e novos protagonismos no acesso ao direito e à justiça; - o velho e o novo pluralismo jurídico; - Nova organização e gestão judiciárias; - Revolução na formação profissional, desde as faculdades de direito até a formação permanente; - Novas concepções de independência judicial; - Uma relação do poder judicial mais transparente com o poder político e a mídia, e mais densa com os movimentos e organizações sociais; - Uma cultura jurídica democrática e não corporativa. ${ }^{29}$

A partir disso, também, influenciado pela tendência mundial no século $X X$, houve forte tendência à desjudicialização dos litígios, caracterizada dentro do processo judicial, pela simplificação processual ou recurso a métodos informais para agilizar as soluções dos processos judiciais; e fora do sistema judicial, o surgimento de estruturas não judiciais de resolução de litígios ${ }^{30}$. Nesse breve estudo não é objetivo o aprofundamento sobre nenhuma delas, mas a identificação delas e sua relação com o multicitado direito colaborativo.

Sabe-se que há inúmeras práticas mencionadas na proposta citadas pelo autor, algumas com êxito. Uma vez que existem diferentes MASC's, é típico que alguns

27 SANTOS, Boaventura Souza. Para uma revolução democrática da justiça. São Paulo: Editora Cortez, 2007, 3 ed. rev. amp., p.21.

28 SANTOS, Boaventura Souza. Para uma revolução democrática da justiça. p.24.

29 SANTOS, Boaventura Souza. Para uma revolução democrática da justiça. p.24-25.

30 PEDROSO, João et al. Percursos da informalização e da desjudicialização por caminhos da reforma da administração da justiça (análise comparativa). Coimbra, Centro de Estudos Sociais, 2001. Disponível em: <http://www.ces.uc.pt/publicacoes/oficina/ficheiros/171.pdf>. Acesso em: 15.dez.2016, p.20. 
RIBEIRO, Fabiano Colusso; HÜLSE, Levi. Direito colaborativo - um novo olhar sobre a resolução de conflitos. Revista Eletrônica Direito e Política, Programa de Pós-Graduação Stricto Sensu em Ciência Jurídica da UNIVALI, Itajaí, v.13, n.3, $3^{\circ}$ quadrimestre de 2018. Disponível em: www.univali.br/direitoepolitica - ISSN 1980-7791

compartilhem notas comuns entre eles, no entanto, cada um tem sua própria identidade e regras peculiares ou próprias de desenvolvimento. Os MASC's que comumente podemos encontrar no ordenamento jurídico mundial são: negociação, conciliação, mediação e arbitragem ${ }^{31}$.

Em primeiro lugar, por meio da negociação, as partes se comunicam para chegar a um acordo, dando a cada uma delas uma questão ${ }^{32}$. Fisher, Willian, Patton na "bíblia" sobre a negociação, esclarecem que rotineiramente as pessoas participam de processos de Negociação [na família, escola, trabalho, trânsito entre outros ambientes], sendo ela "um meio básico de conseguir o que se quer de outrem. É uma comunicação bidirecional concebida para chegar a um acordo, quando você e o outro lado têm alguns interesses em comum e outros opostos". ${ }^{33}$

Por essência, o ser humano é um negociador ${ }^{34}$. Quando a negociação prospera, podemos falar de uma transação ou contrato entre partes, que as vincula, e pode chegar a observar formalidades ou ser homologado por um juiz tal acordo, caso em que terá os efeitos de um título executivo se ocorrer um litígio subsequente.

Por sua vez, a conciliação e a mediação apresentam-se como dois meios de tratamento de conflitos que visam o restabelecimento das relações sociais e a busca da paz. ${ }^{35}$ Já a arbitragem é um método de resolução dos conflitos no qual as partes consensualmente escolhem um ou mais árbitros, para que conheça do conflito e proferida uma decisão que será vinculante entre as partes, nada mais do uma jurisdição privada.

Nas palavras de Moraes e Spengler na "conciliação, o objetivo é o acordo, ou seja, as partes, mesmo adversárias, devem chegar a um acordo para evitar o processo

31 GOUVEIA, Mariana F. Curso de resolução alternativa de litígios. 2.ed. Coimbra: Almedina, 2012. p. 18.

32 BOWE, Guy. Skills and Values: Alternative Dispute Resolution: Negotiation, Mediation, Collaborative Law, and Arbitration. Arbitration Law Review. Yearbook on Arbitration and Mediation. v. 6, Article 27, 2014, p. 469.

33 FISHER, Roger; WILLIAN, Ury; PATTON, Bruce. Como Chegar ao sim: a negociação de acordos sem concessões. 2.ed. Rio de Janeiro: Imago, 1994. p. 216.

34 ZAJDSNAJDER, Luciano. Teoria e Prática da Negociação. Rio de Janeiro: José Olympio, 1985.

35 CHMATALIK, Cristiane Conde. JUNIOR, Américo Bedê. Conciliação - As Técnicas de Negociaçã e a Nova Política Judiciária instituída pelo novo CPC na Justiça Federal. In: Justiça Multiportas: mediação, conciliação, arbitragem e outros meios de solução adequada para conflitos. Ed. Juspodvim, Salvador, 2016, pp. 434-436. 
RIBEIRO, Fabiano Colusso; HÜLSE, Levi. Direito colaborativo - um novo olhar sobre a resolução de conflitos. Revista Eletrônica Direito e Política, Programa de Pós-Graduação Stricto Sensu em Ciência Jurídica da UNIVALI, Itajaí, v.13, n.3, $3^{\circ}$ quadrimestre de 2018. Disponível em: www.univali.br/direitoepolitica - ISSN 1980-7791

judicial ou para nele pôr um ponto final, se por ventura ele já existe". Nesta modalidade de autocomposição, o conciliador participa ativamente, sugerindo, interfere, aconselha; já na Mediação "o mediador facilita a comunicação sem induzir as partes ao acordo". ${ }^{36}$

De outro lado, convém anotar que, segundo Calmon, a Conciliação pode ser classificada conforme o momento em que é realizada. Nesse raciocínio cronológico, pode-se afirmar que a conciliação ocorre antes da propositura de uma ação (préprocessual) ou durante o andamento do processo(processual). $E$, de um ponto de vista topológico, a conciliação distingui-se em extraprocessual (fora dos autos) ou endoprocessual (dentro dos autos). ${ }^{37}$

O conceito de mediação também é melhor definido por Serpa, o qual define que a Mediação "é mais do que essa conformidade, porque seu objetivo não é enquadrar a disputa em nenhuma estrutura legal preestabelecida, mas conduzir a disputa à criação de uma estrutura própria mediante a construção de normas relevantes para as partes". ${ }^{38}$

Christopher W. Moore em definição precisa, diz que a mediação é

[...] interferência em uma negociação ou em um conflito de uma terceira parte aceitável, tendo um poder de decisão limitado ou não-autoritário, e que ajuda as partes envolvidas a chegarem voluntariamente a um acordo, mutuamente aceitável com relação às questões em disputa. Além de lidar com questões fundamentais, a mediação pode também estabelecer ou fortalecer relacionamentos de confiança e respeito entre as partes ou encerrar relacionamentos de uma maneira que minimize os custos e danos psicológicos. ${ }^{39}$

Por sua vez, em arremate, Besso descreveu o conceito de mediação na legislação italiana como sendo um procedimento no qual um terceiro facilita a comunicação e a

\footnotetext{
36 MORAIS, José Luis Bolzan de; SPENGLER, Fabiana Marion. Mediação e Arbitragem: alternativas à Jurisdição. 3.ed. Porto Alegre: Livraria do Advogado, 2012. p. 203-204.

37 CALMON, Petronio. Fundamentos da mediação e da conciliação. 2.ed. Brasília, DF: Gazeta Jurídica, 2013. p. 135.

38 SERPA, Maria Nazareth. Teoria e Prática da Mediação de Conflitos. Rio de Janeiro: Lumen Juris, 1999. p. 146.

39 MOORE, Cristopher W. O Processo de Mediação: estratégias práticas para a resolução de conflitos. Tradução de Magda França Lopes. Porto Alegre: Ed. Artmed. 1998, p. 28.
} 
RIBEIRO, Fabiano Colusso; HÜLSE, Levi. Direito colaborativo - um novo olhar sobre a resolução de conflitos. Revista Eletrônica Direito e Política, Programa de Pós-Graduação Stricto Sensu em Ciência Jurídica da UNIVALI, Itajaí, v.13, n.3, $3^{\circ}$ quadrimestre de 2018. Disponível em: www.univali.br/direitoepolitica - ISSN 1980-7791

negociação entre as partes em conflito para ajudá-las a chegarem voluntariamente a um acordo, agindo o mediador com estrita neutralidade. ${ }^{40}$

Ainda, resta definir a arbitragem, o que Rocha o faz com grande clareza: "a arbitragem pode ser definida como um meio de resolver litígios civis, atuais ou futuros, sobre direitos patrimoniais disponíveis, através do árbitro ou árbitros privados, escolhidos pelas partes, cujas decisões produzem os mesmos efeitos jurídicos das sentença proferidas pelos órgãos do Poder Judiciário". ${ }^{41}$

Lemos e Lemos conceitua a arbitragem como juízo jurisdicional e extrajudicial, no qual pessoas capazes de contratar escolhem livremente árbitros para dirimir litígio determinado (presente) ou determinável (futuro e incerto) de natureza patrimonial indisponível. ${ }^{42}$

Nohmi aduz que arbitragem é o mecanismo de solução pacífica de conflitos, pelo qual as partes envolvidas numa disputa qualquer escolhem, de comum acordo, um ou mais árbitros, para conhecer das razões controvertidas e Ihes atribuir uma decisão, que deverá ser escolhida como obrigatória. ${ }^{43}$

Apurado os variados conceitos dos principais métodos alternativos de resolução de conflitos (MASC's ou ADR's), observa-se que diferem do direito colaborativo apenas na essência, mas há inúmeros pontos comuns que destacamos a seguir. O direito colaborativo, como foi dito acima, é um método autocompositivo de resolução de litígios, sendo, em todos os momentos, as partes conduzem o procedimento, portanto, a qualquer momento podem chegar em um acordo ou encerrar o procedimento, observando-se seus interesses comuns por meio do dialogo entre elas, auxiliadas por seus respectivos advogados.

40 "Mediazione è "I'attività, comunque denominata, svolta da un terzo imparziale e finalizzata ad assistere due o più soggetti sia nella ricerca di un accordo amichevole per la composizione di una controversia, sia nella formulazione di una proposta per la risoluzione della stessa". BESSO, Chiara. La Mediazione Italiana: Definizioni e Tipologie. Revista Eletrônica de Direito Processual, Rio de Janeiro, v.6, n.4, p. 248-269, jul./dez. 2010. Disponível em: < http://www.arcos.org.br/periodicos/revistaeletronica-de-direito-processual/volume-vi/la-mediazione-italiana-definizioni-e-tipologie>. Acesso em: 25 jan. 2018. p. 33.

41 ROCHA, José de Albuquerque. Lei da arbitragem. São Paulo: Atlas, 2008, p. 23.

42 LEMOS, Luciano Braga; LEMOS, Rodrigo Braga. A arbitragem e o direito. Belo Horizonte: Mandamentos Editora, 2003, p. 7.

43 NOHMI, Antônio Marcos. Arbitragem internacional: mecanismos de solução de conflitos entre estados. Editora Del Rey. Belo Horizonte, FCH-FUMEC, 2005, pp. 76-77. 
RIBEIRO, Fabiano Colusso; HÜLSE, Levi. Direito colaborativo - um novo olhar sobre a resolução de conflitos. Revista Eletrônica Direito e Política, Programa de Pós-Graduação Stricto Sensu em Ciência Jurídica da UNIVALI, Itajaí, v.13, n.3, $3^{\circ}$ quadrimestre de 2018. Disponível em: www.univali.br/direitoepolitica - ISSN 1980-7791

Entretanto, dentre os vários métodos alternativos de resolução de conflitos (MASC's ou ADR's), observa-se também que alguns deles compartilham semelhanças, porém, cada um tem suas características e regras próprias de desenvolvimento. Aliás, a doutrina especialmente no direito estadunidense descreve o direito colaborativo, como um novo ADR, paralelo aos demais existentes. ${ }^{44}$

Como dito supra, na negociação as partes por meio da comunicação discutem determinado conflito com intuito chegar a um acordo, dando a cada um em qualquer questão. Há inúmeros estudos, modalidades e estilos de negociação, porém os dois modelos replicados popularmente são a negociação adversarial e cooperativa ${ }^{45}$. 0 direito colaborativo, enquanto 'prática colaborativa', é uma forma de negociação cooperativa entre as partes, assistidas por profissionais, com o mesmo objetivo: chegar a um acordo.

Ressalta-se duas diferenças claras entre a negociação propriamente dita e as práticas colaborativas. Por um lado, a negociação destina-se encerrar um procedimento judicial ou, mesmo conduzi-lo, ainda que de maneira extrajudicial, mas com posterior chancela do Poder Judiciário; ao contrário do Direito Colaborativo, que foi concebido para evitar completamente os Tribunais; e, noutro giro, é necessária a participação ativa de advogados no processo colaborativo, os quais são proibidos de atuar em eventual processo judicial futuro sobre a controvérsia; o que não ocorre na negociação propriamente dita, pois os advogados que participarem dela, acaso não haja um acordo, são livres para assistir seus clientes em eventual processo contencioso ou continuar a litigar contra a mesma parte. ${ }^{46}$

Por conseguinte, a conciliação é outro mecanismo consensual que é o mais utilizado pelo Poder Judiciário ${ }^{47}$, apesar de genuinamente judicial, pode ser utilizada fora da

\footnotetext{
44 HOFFMAN, David A. Colliding Worlds of Dispute Resolution: Towards a Unified Field Theory of ADR. Journal of Dispute Resolution, 2008, p.14. Disponível em : <https://scholarship.law.missouri.edu/jdr/vol2008/iss1/4>. Acesso em: 05.jan.2018.
}

45 BOWE, Guy. Skills and Values: Alternative Dispute Resolution: Negotiation, Mediation, Collaborative Law, and Arbitration. Arbitration Law Review. Yearbook on Arbitration and Mediation. v. 6, Article 27, 2014, p. 469.

46 BOWE, Guy. Skills and Values: Alternative Dispute Resolution: Negotiation, Mediation, Collaborative Law, and Arbitration. Arbitration Law Review. Yearbook on Arbitration and Mediation. v. 6, Article 27, 2014, pp. 469-470.

47 O Conselho Nacional de Justiça estimula tradicionalmente este método, o qual é o mais tradicional e antigo no Judiciário Brasileiro, com a realização de mutirões anuais de conciliação, tendo inclusive disponibilizado a realização de programas e ações. Maiores informações vide sítio: 
RIBEIRO, Fabiano Colusso; HÜLSE, Levi. Direito colaborativo - um novo olhar sobre a resolução de conflitos. Revista Eletrônica Direito e Política, Programa de Pós-Graduação Stricto Sensu em Ciência Jurídica da UNIVALI, Itajaí, v.13, n.3, $3^{\circ}$ quadrimestre de 2018. Disponível em: www.univali.br/direitoepolitica - ISSN 1980-7791

Justiça, aliás, no Brasil é uma etapa obrigatória no processo judicial. ${ }^{48}$ Através da conciliação, as partes eles chegarem a um acordo para um terceiro, o conciliador jurídico, antes de iniciar o processo. Esse terceiro nunca decide, mas o acordo tem de ser ratificado antes dele. No caso de que as partes não chegarem a acordo, têm a possibilidade de atendimento via aberta judicial. ${ }^{49}$ Este sistema, portanto, apresenta as mesmas diferenças indicadas anteriormente com a prática colaborativa.

Tocante à mediação e o direito colaborativo, são notórias as semelhanças entre os institutos, tais como a importância do protagonismo das partes, a gestão do conflito por meio de diálogo e consenso, voluntariedade do procedimento, a confidencialidade e a transparência ou a importância de trabalhar com técnicas de comunicação assertivas. ${ }^{50}$

Por fim, Coruga em sua analise do Direito Colaborativo na Espanha identificou os principais pontos comuns entre mediação e direito colaborativo, quais sejam, i) Voluntariedade, logo, significa que eles não são forçados a participar de qualquer do procedimento, tal qual na mediação; ii) Negociação, Mediação e Direito Colaborativo - o procedimento gira em torno dos interesses das partes, na medida em que as circunstâncias trazidas pelas partes comporá o acordo, o qual terá a contribuição de ambos; iii) Confidencialidade, traduzida no regramento em que as informações sobre os procedimentos de mediação, bem como no procedimento colaborativo, são absolutamente confidenciais, e não pode não ser revelada a terceiros não envolvidos nesses procedimentos; iv) Fator econômico e emocional - redução de custos com processo judicial e pela duração diminui o desgaste entre as partes, além disso, haverá uma solução adaptada ao caso específico, não imposta por um terceiro; v) Controle do processo - as partes são protagonista, uma vez que dependem deles para chegar a um acordo ou não. Embora a intervenção de um terceiro neutro, no

<http://www.cnj.jus.br/programas-e-acoes/conciliacao-e-mediacao-portal-da-conciliacao/movimentoconciliacao-mediacao>. Acesso em: 15.jan.2018.

${ }^{48}$ A obrigatoriedade consta regulado no artigo $334, \S \S 4^{\circ}, 5^{\circ}$ e $6^{\circ}$ do Código de Processo Civil.

49 CABRAL, Antônio do passo; CUNHA, Leonardo Carneiro da. Negociação Direta ou resolução colaborativa de disputas (Collaborative Law): "mediação sem mediador". In: Justiça Multiportas: mediação, conciliação, arbitragem e outros meios de solução adequada para conflitos. Ed. Juspodvim, Salvador, 2016, p.712 .

50 P. Oswin Chrisman, Gay G. Cox, and Petra Novotna, Collaborative Practice Mediation: Are We Ready to Serve this Emerging Market. Pepperdine Dispute Resolution Law Journal n. 6, Iss. 3, 2006, Disponível em: <http://digitalcommons.pepperdine.edu/drlj/vol6/iss3/4>. Acesso em: 22.dez.2017, p. 452. 
RIBEIRO, Fabiano Colusso; HÜLSE, Levi. Direito colaborativo - um novo olhar sobre a resolução de conflitos. Revista Eletrônica Direito e Política, Programa de Pós-Graduação Stricto Sensu em Ciência Jurídica da UNIVALI, Itajaí, v.13, n.3, $3^{\circ}$ quadrimestre de 2018. Disponível em: www.univali.br/direitoepolitica - ISSN 1980-7791

caso de mediação, ou, dos procuradores no direito colaborativo. Mas, é certo que apenas as partes, sempre elas que decidem se atinge ou não uma solução consensual. 51

Ainda, pode-se ressaltar que nas práticas colaborativas não é necessária a neutralidade ou a imparcialidade que, por sua vez, inspiram os princípios gerais do exercício da mediação. À medida que as partes são representadas por advogados (colaborativos) durante a negociação e são aconselhados por eles, observando-se as normas éticas constantes nas normas padrões ${ }^{52}$ (Uniform Collaborative Law Rules and Act) e o acordo firmado inicialmente pelas partes. O Advogado colaborativo tenta alcançar os interesses de seus clientes e para isso negocia com eles com a outra parte que também ser assistida na negociação por outros profissionais de qualquer outra área. ${ }^{53}$

No geral, falar de Direito Colaborativo é fazê-lo a partir de uma negociação colaborativa estruturada entre quatro ou mais pessoas, diferente de outros métodos citados acima, em que o número de participantes é inferior e não há vinculação necessária de advogados para assistir as partes, sendo facultativa. Então, as partes, que não são 'opostos', intervêm no procedimento como protagonistas incontestáveis, mas auxiliados por profissionais que são especialistas nas técnicas próprias dos sistemas de ADR/MASC's. (negociação, mediação e conciliação), sem qualquer limitação numérica ou técnica. ${ }^{54}$

Os advogados colaborativos procuram satisfazer o interesse das partes (ambos) em estratégias de "ganha-ganha" ("win-win"), nas quais se pretende que elas saem satisfeito compartilhando o benefício. Em suma, os profissionais colaboram para

51 LOREDO COLUNGA, M.. El método colaborativo: nuevos horizontes en el marco de la autocomposición. Revista de Justicia Restaurativa, Violencia de Género, Justicia Restaurativa y Mediación. Editora Grupo Wolters Kluwer. n.2, 2011, p. 541

52 Sobre o assunto, conferir normas sugeridas pela Academia Internacional de Profissionais Colaborativos (IACP), na qual editou documento com "Padrões de Conduta e de Ética" a serem seguidos pelos Advogados Colaborativos. Disponível em: <https://docs.wixstatic.com/ugd/e910af_cd79a545d5ce4538b01160601a144c36.pdf>. Acesso em: 20.jan. 2018.

53 HOFFMAN, David. TESLER, Pauline. Collaborative Law and the Use of Settlement Counsel. The Alternative Dispute Resolution Practice Guide. B. Roth, ed. 2002. Disponível em: <https://blc.law/wpcontent/uploads/2016/12/2005-07-collaborative-law-and-settlement-counselbranchmainlanguagedefault.pdf>. Acesso em: 05.jan.2018.

54 SIMMONS, Martha Emily. Increasing Innovation in Legal Process: The Contribution of Collaborative Law. PhD Theses. Paper 11, 2015, p. 29. 
RIBEIRO, Fabiano Colusso; HÜLSE, Levi. Direito colaborativo - um novo olhar sobre a resolução de conflitos. Revista Eletrônica Direito e Política, Programa de Pós-Graduação Stricto Sensu em Ciência Jurídica da UNIVALI, Itajaí, v.13, n.3, 30 quadrimestre de 2018. Disponível em: www.univali.br/direitoepolitica - ISSN 1980-7791

facilitar acordos rentáveis para todos os seus clientes, mas as partes também participam ativamente e mantêm, em todos os momentos, o controle de decisões sobre a possibilidade ou não de acordo, fato que os diferencia dos demais ADR/MASC's. (negociação, mediação e conciliação). ${ }^{55}$

Finalmente, a arbitragem é parte do grupo dos métodos heterocompositivos de resolução de litígios ${ }^{56}$, o que implica que será uma pessoa neutra e imparcial, ou painel de arbitros, que vai decidir o conflito, por eles escolhidas e que tenham habilidades técnicas ${ }^{57}$. Por esta razão, na arbitragem são as partes que, através de um acordo assinado, decidem submeter-se a esta forma de resolução de litígios.

Assim este procedimento termina com uma resolução final, ditando o terceiros imparciais [Painel de árbitros] ou Árbitro, chamado sentença arbitral, que é diretamente executável em um processo executivo judicial. A principal diferença com a arbitragem é que é um terceiro que decide e não partes, é em última análise, um juiz privado, as partes decidam por si mesmos a solução que melhor Ihes convier, sem deixa uma terceira pessoa que decidir por eles. ${ }^{58}$

\section{A ADOÇÃO DE PRÁTICAS COLABORATIVAS OU DIREITO COLABORATIVO NO ORDENAMENTO JURÍDICO BRASILEIRO}

Como vimos, o direito colaborativo faz parte das transformações idealizadas por Boaventura de Sousa Santos e traduzem um "novo paradigma jurídico e judiciário", mas que não serão a panaceia na resolução dos conflitos sociais, mas um instrumento democrático de inclusão social e política. Por exemplo, os resultados obtidos com as

\footnotetext{
55 HOFFMAN, David. TESLER, Pauline. Collaborative Law and the Use of Settlement Counsel. The Alternative Dispute Resolution Practice Guide. B. Roth, ed. 2002. Disponível em: <https://blc.law/wpcontent/uploads/2016/12/2005-07-collaborative-law-and-settlement-counselbranchmainlanguagedefault.pdf>. Acesso em: 05.jan.2018.

56 "No Estado Constitucional, os conflitos podem ser resolvidos de forma heterocompositiva ou autocompositiva. Há heterocomposição quando um terceiro resolve a ameaça ou crise de colaboração na realização do direito material entre as partes. Há autocomposição quando as próprias partes resolvem seus conflitos" MARINONI, Luiz Guilherme. Et. al. Novo curso de direito processual civil: teoria do processo civil. v.1. 2ed. São Paulo, 2016, p.187.
}

57 BOWE, Guy. Skills and Values: Alternative Dispute Resolution: Negotiation, Mediation, Collaborative Law, and Arbitration. Arbitration Law Review. Yearbook on Arbitration and Mediation. v. 6, Article 27, 2014, p. 482.

58 BOWE, Guy. Skills and Values: Alternative Dispute Resolution: Negotiation, Mediation, Collaborative Law, and Arbitration.p.482. 
RIBEIRO, Fabiano Colusso; HÜLSE, Levi. Direito colaborativo - um novo olhar sobre a resolução de conflitos. Revista Eletrônica Direito e Política, Programa de Pós-Graduação Stricto Sensu em Ciência Jurídica da UNIVALI, Itajaí, v.13, n.3, 30 quadrimestre de 2018. Disponível em: www.univali.br/direitoepolitica - ISSN 1980-7791

recentes reformas processuais aqui no Brasil ainda são tímidos, especialmente diante das últimas estatísticas divulgadas pelo Conselho Nacional de Justiça (CNJ).

No Brasil, a informalização da Justiça iniciou fortemente somente após a chamada reforma do Poder Judiciário, inaugurada pela Emenda Constitucional n. 45 e os "Pactos de Estado por um Judiciário mais Rápido e Republicano, firmado pelos Chefes dos três Poderes"59, ocupando espaços jurisdicionais alternativos e desenvolvendose mecanismos consensuais de justiça em espaços comunitários. Com essa informalização, cresceu a desjuridificação (desjudicializacão), ou seja, a adesão a meios informais de solução de controvérsias.

Isso fica mais acentuado no Brasil a partir da edição pelo Conselho Nacional de Justiça $(\mathrm{CNJ})$, órgão colegiado de administração e controle do Poder Judiciário, da resolução n. 125/2010, uma verdadeira política pública de tratamento dos conflitos. A aludida resolução surge como "Política Judiciária Nacional de Tratamento Adequado dos Conflitos de Interesses no Âmbito do Poder Judiciário", e o maior exemplo de uma proposta afirmativa e concreta para minimizar os grandes problemas de volumes de processos judiciais e aumentos dos litígios, uma verdadeira política pública sustentável. 60

Entretanto, Barbosa Moreira registra uma eloquente crítica às soluções milagrosas quando se trata de premonições sobre o futuro do Poder Judiciário, especialmente sobre os métodos alternativos de resolução de conflitos (MASC'S). O autor listou na década de 2000 grandes 4 (quatro) mitos que atualmente permanecem em discussão, quais sejam, i) "a rapidez acima de tudo" - acelerar a prestação

\footnotetext{
59 Documentos firmados pelo Estado brasileiro no qual compromete-se em fomentar diversas medidas, dentre elas estímulo à desjudicialização e a diminuição da judicialização, em especial promover: o "aprimoramento da prestação jurisdicional, mormente pela efetividade do princípio constitucional da razoável duração do processo e pela prevenção de conflitos; fortalecer a mediação e a conciliação, estimulando a resolução de conflitos por meios autocompositivos, voltados à maior pacificação social e menor judicialização; incrementar medidas tendentes a assegurar maior efetividade ao reconhecimento dos direitos, em especial a concessão e revisão de benefícios previdenciários e assistenciais". BRASIL. II PACTO REPUBLICANO DE ESTADO POR UM SISTEMA DE JUSTIÇA MAIS ACESSÍVEL, ÁGIL E EFETIVO. Disponível em: <http://www.planalto.gov.br/ccivil_03/outros/iipacto.htm>. Acesso em: 10.dez.2017. Há também disponível em: http://www2.stf.jus.br/portalStfInternacional/cms/verConteudo.php?sigla=portalStfDestaque_pt_br\&i dConteudo $=173547>$.

60 BRASIL. Conselho Nacional de Justiça. Resolução no 125, de 29 de novembro de 2010. Dispõe sobre a Política Judiciária Nacional de tratamento adequado dos conflitos de interesses no âmbito do Poder Judiciário e dá outras providências. Disponível em: <http://www.cnj.jus.br/busca-atosadm?documento=2579>. Acesso em: 01.fev.2017.
} 
RIBEIRO, Fabiano Colusso; HÜLSE, Levi. Direito colaborativo - um novo olhar sobre a resolução de conflitos. Revista Eletrônica Direito e Política, Programa de Pós-Graduação Stricto Sensu em Ciência Jurídica da UNIVALI, Itajaí, v.13, n.3, $3^{\circ}$ quadrimestre de 2018. Disponível em: www.univali.br/direitoepolitica - ISSN 1980-7791

jurisdicional a qualquer preço historicamente não tem sido uma iniciativa; ii) "a formula mágica" - Excesso de entusiasmo com ideias que não culturalmente não funcionam no Brasil, citando, o exemplo da Arbitragem que já fora tratada como panacéia da justiça, mas o tempo provou o contrário; iii) "supervalorização de modelos estrangeiros" - a difícil tarefa de trazer modelos prontos e implanta-los acriticamente em nossso ordenamento, que costumam não resolver problemas, mas criar mais; e iv) "onipotência da norma" - o império da lei ou excesso legislativo, ansia por sucessivas reformas sem atentar para o cotidiano forense. ${ }^{61}$

Nesse ritmo argumentativo, o enfrentamento da hiperjudicialização, segundo as críticas dos estudos de Falcão, Arguelhes e Recondo, perpassa pelo engajamento do Supremo Tribunal Federal, o qual tem um comportamento fomentador da judicialização ao estimular a litigiosidade individual, ou como dizem os autores, "o dilema do Supremo: os ministros agem contra o colegiado e, por ação ou omissão, assumem um poder de fazer política e políticas públicas que não Ihes pertence". ${ }^{62}$

Por ora, convém deixar expresso que o desenvolvimento do direito colaborativo, dependerá fatalmente das circunstâncias históricas, políticas e culturais, para que tenha sucesso, acaso seja regulamentada no Brasil. O fato é que o direito colaborativo é uma proposta coerente e necessária construída a partir de práticas colaborativas já existentes, mas empregadas de variadas formas, sendo válida e atual a crítica de Barbosa Moreira, de que nada adianta "[...]combater enfermidades que não se conhecem bem, é desferir às cegas golpes na escuridão. Para saber em que direção nos devemos mover, cumpre ter uma imagem tão exata quanto possível da situação atual". 63

No Brasil vigora o monopólio estatal da jurisdição como órgão exclusivo em julgamentos $^{64}$, o que segundo Candido Rangel Dinamarco é herança cultural do direito romano, o qual passou por uma transformação em que houve a absorção

61 BARBOSA MOREIRA, José Carlos. O futuro da justiça: alguns mitos. Revista de Processo, v. 102, abr./jun. 2001, pp. 228-238.

62 FALCÃO, Joaquim.; ARGUELHES, Diego W.; RECONDO, Felipe.; Onze supremos: o supremo em 2016. Belo Horizonte (MG), 2017, p.

63 BARBOSA MOREIRA, José Carlos. O futuro da justiça: alguns mitos. Revista de Processo, v. 102, abr./jun. 2001, pp. 228-238.

64 Vide artigo 50, inciso, CRFB. 
RIBEIRO, Fabiano Colusso; HÜLSE, Levi. Direito colaborativo - um novo olhar sobre a resolução de conflitos. Revista Eletrônica Direito e Política, Programa de Pós-Graduação Stricto Sensu em Ciência Jurídica da UNIVALI, Itajaí, v.13, n.3, 30 quadrimestre de 2018. Disponível em: www.univali.br/direitoepolitica - ISSN 1980-7791

estatal da atividade de solucionar conflitos, antes de responsabilidade do próprio cidadão. ${ }^{65}$

Tal a centralização dos conflitos no Poder Judiciário não é o um meio jurídico de permitir as pessoas o acesso a uma ordem jurídica justa e sustentável, esta garantia poderá ser sempre reclamada em casos de lesão ou de ameaça de violação de direitos e interesses dos particulares por medidas e decisões provenientes de outros poderes, autoridades públicas e órgãos delegatórios da Justiça, a ponto de afrontar a ordem jurídica justa ${ }^{66}$.

A propósito, sobre o tema Marinoni esclarece:

No Estado Constitucional, os conflitos podem ser resolvidos de forma heterocompositiva ou autocompositiva. Há heterocomposição quando um terceiro resolve a ameaça ou crise de colaboração na realização do direito material entre as partes. Há autocomposição quando as próprias partes resolvem seus conflitos. ${ }^{67}$

Segundo o referido autor, a jurisdição deve ser encarada como a "ultima ratio", tendo a legislação processual atual expressamente incentivado, preferencialmente, a resolução dos conflitos por meios alternativos ${ }^{68}$. Mas não faz qualquer sentido implementar a política de resolução alternativa de conflitos exclusiva ou pertencente apenas ao Judiciário, como inicialmente prevista pelo Conselho Nacional de Justiça CNJ, atividades que podem ser melhor resolvidas nas esferas administrativas. Tal prática é incompatível com o raciocínio da própria política pública e acaba afastando da própria sociedade outros caminhos para resolver seus problemas sociais quando estes podem ser resolvidos por métodos de autocomposição e por intermédio de outros agentes.

\footnotetext{
65 DINAMARCO, Candido. Instituições de Direito Processual Civil. v.1. São Paulo, Malheiros, p. 121.

66 DINAMARCO, Candido. Instituições de Direito Processual Civil. v.1. São Paulo, Malheiros, p. 122.

67 MARINONI, Luiz Guilherme. Et. al. Novo curso de direito processual civil: teoria do processo civil. v.1. 2ed. São Paulo, 2016, p.187.

68 Art. $3^{\circ}$ do Código de Processo Civil:"Não se excluirá da apreciação jurisdicional ameaça ou lesão a direito. $\S 1^{\circ}$ É permitida a arbitragem, na forma da lei. $\S 2^{\circ} \mathrm{O}$ Estado promoverá, sempre que possível, a solução consensual dos conflitos. $\S 3^{\circ}$ A conciliação, a mediação e outros métodos de solução consensual de conflitos deverão ser estimulados por juízes, advogados, defensores públicos e membros do Ministério Público, inclusive no curso do processo judicial.
} 
RIBEIRO, Fabiano Colusso; HÜLSE, Levi. Direito colaborativo - um novo olhar sobre a resolução de conflitos. Revista Eletrônica Direito e Política, Programa de Pós-Graduação Stricto Sensu em Ciência Jurídica da UNIVALI, Itajaí, v.13, n.3, $3^{\circ}$ quadrimestre de 2018. Disponível em: www.univali.br/direitoepolitica - ISSN 1980-7791

Como corolário deste processo de transformação do Poder Judiciário brasileiro foram editados novos diplomas legislativos que dão ênfase aos meios alternativos de resolução de conflitos (MASC's ou ADR's), quais sejam, a Lei n. 13.140/2015 (Lei da mediação) e a reforma na Lei de Arbitragem (Lei n. 9.307/96) trazida pela Lei n. 13.129/2016, bem assim a inclusão da obrigatoriedade da realização da audiência de conciliação e medição como etapa do procedimento comum.

Fica constatada a necessidade da superação do paradigma "vencedor" e "perdedor", individualista, partindo-se para um processo cooperativo, no qual as partes devem contribuir de maneira sustentável para resolução do litígio, tal qual a ideia do direito colaborativo. ${ }^{69} \mathrm{Em}$ verdade, tal modelo busca dar efetividade ao comando constitucional da razoável duração do processo, nesse ambiente de "litigiosidade massiva", consoante a lição de Humberto Theodoro Júnior. ${ }^{70}$

Entretanto, o referido autor adverte claramente que essas são apostas, destacandose como o primeiro e principal o "Novo CPC", Lei n. 13.105/2015, como a principal delas, todavia, essas são excelentes ferramentas, mas sua utilização depende de mudanças estruturais, culturais da sociedade e na mentalidade do Poder Judiciário ${ }^{71}$.

Nesse ponto, importante ressaltar que a Lei de Mediação (Lei no 13.140/2015) e o novo Código de Processo Civil (Lei no 13.105/2015) determinam que os tribunais criem os Centros Judiciários de Solução Consensual de Conflitos (Cejuscs). Segundo a Lei de Mediação, "os tribunais criarão centros judiciários de solução consensual de conflitos, responsáveis pela realização de sessões e audiências de conciliação e mediação, pré-processuais e processuais, e pelo desenvolvimento de programas destinados a auxiliar, orientar e estimular a autocomposição". ${ }^{72}$ Ou seja, há

\footnotetext{
69 BRASIL. Ministério da Justiça. Exposição de motivos ao anteprojeto de Lei de Mediação. Brasília: Congresso Nacional, 2013.

<http://www.euroarbitragem.com.br/pt/anexo/Anteprojeto\%20-

\%20Lei\%20de\%20Media\%C3\%A7\%C3\%A30\%20(Comiss\%C3\%A30\%20MJ)\%20[Exp.\%20Motivos].p df $>$. Acesso em: 29.jul.2016.
}

70 THEODORO Júnior, Humberto Junior. Novo CPC - Fundamentos e sistematização - Humberto Theodoro Júnior, Dierle Nunes, Alexandre Melo Franco Bahia, Flávio Quinaud Pedron - Rio de Janeiro: Forense, 2015, ps. 141-143.

71 THEODORO Júnior, Humberto Junior. Novo CPC - Fundamentos e sistematização - Humberto Theodoro Júnior, Dierle Nunes, Alexandre Melo Franco Bahia, Flávio Quinaud Pedron - Rio de Janeiro: Forense, 2015, ps. 146.

72 BRASIL. Conselho Nacional de Justiça. LEI No 13.140, DE 26 DE JUNHO DE 2015. Disponível em: <http://www.planalto.gov.br/ccivil_03/_ato2015-2018/2015/Lei/L13140.htm >. Acesso em: 10.fev.2017. 
RIBEIRO, Fabiano Colusso; HÜLSE, Levi. Direito colaborativo - um novo olhar sobre a resolução de conflitos. Revista Eletrônica Direito e Política, Programa de Pós-Graduação Stricto Sensu em Ciência Jurídica da UNIVALI, Itajaí, v.13, n.3, $3^{\circ}$ quadrimestre de 2018. Disponível em: www.univali.br/direitoepolitica - ISSN 1980-7791

possibilidade da resolução do conflito de forma preventiva e repressiva, antes ou depois de um processo judicial, o que formalmente não existia no ordenamento jurídico brasileiro, e sem sombra de dúvida é a via eleita que merece mais incentivo e desenvolvimento.

Em paralelo aos instrumentos citados surgiu também recentemente a iniciativa de trazer para o Brasil as práticas colaborativas e com isso o desenvolvimento do direito colaborativo. Em 2011, profissionais do Rio de Janeiro e São Paulo envolvidos em capacitação no exterior sobre direito colaborativo formaram um grupo de discussão e estudo do método, bem como já tem aplicado o método em seus Estados, mas ainda há pouco interesse pelo tema. ${ }^{73}$

Mas segundo Cabral et al, as técnicas ou práticas colaborativas podem ser utilizadas no ordenamento jurídico brasileiro vigente, porquanto o Código de Processo Civil incentiva e visa promover o modelo de processo cooperativo, logo, fomenta a prática de soluções autocompositivas dos conflitos, sendo a tônica desta lei recentemente publicada, pois admite convenções processuais ou negócios jurídicos processuais e prevê expressamente os princípios da cooperação, boa-fé, lealdade, entre outros como cláusula geral que indicam o verdadeiro mens legis. ${ }^{74}$

Em igual norte, inaugurando este espírito colaborativo o recente reformulado Código de Ética e Disciplina da Ordem dos Advogados do Brasil (OAB), prevê agora no artigo 20, inciso VI: "estimular, a qualquer tempo, a conciliação e a mediação entre os litigantes, prevenindo, sempre que possível, a instauração de litígios;". 75

Vasconcelos em sua obra também reenquadra a atividade advocatícia na sociedade contemporânea, ao dissertar que é preciso transformar a "mentalidade e postura dos

\footnotetext{
73 DENARDI, Eveline Gonçalves; MOURA, Isabel Cristina de; FERNANDES, Mariana Correa. As práticas colaborativas como um recurso para as situações de divórcio. Revista da Faculdade de Direito da UFRGS, Porto Alegre, n. 36, vol. esp., p. 56-72, out. 2017. Ainda sobre as práticas colaborativas, ver sítio eletrônica: www.praticascolaborativas.com.br.
}

74 CABRAL, Antônio do passo; CUNHA, Leonardo Carneiro da. Negociação Direta ou resolução colaborativa de disputas (Collaborative Law): "mediação sem mediador". In: Justiça Multiportas: mediação, conciliação, arbitragem e outros meios de solução adequada para conflitos. Ed. Juspodvim, Salvador, 2016, p.722.

75 ORDEM DOS ADVOGADOS DO BRASIL. Resolução no 02, de 19 de outubro de 2015. Aprova o Código de Ética e Disciplina da Ordem dos Advogados Brasileiros. Disponível em:< http://s.oab.org.br/PDF/CFOAB-CED.pdf>. Acesso em: 15.jan.2018. 
RIBEIRO, Fabiano Colusso; HÜLSE, Levi. Direito colaborativo - um novo olhar sobre a resolução de conflitos. Revista Eletrônica Direito e Política, Programa de Pós-Graduação Stricto Sensu em Ciência Jurídica da UNIVALI, Itajaí, v.13, n.3, $3^{\circ}$ quadrimestre de 2018. Disponível em: www.univali.br/direitoepolitica - ISSN 1980-7791

advogados" para sejam mais colaborativos, negociadores e procurem soluções mais rápidas e adequadas aos clientes. Para tanto a aludida propõe que os advogados substituam a atividade postulatória por uma postura negociadora, de assessoria e consultoria, tal qual é o direito colaborativo. ${ }^{76}$

Do ponto de vista mais pragmático, Da Silva propõe uma reflexão sobre a inserção de cláusula de mediação em todo e qualquer negócio jurídico, frente aos princípios contratuais, uma vez que estes são os pilares de qualquer instrumento contratual. Isso porque tal comprometimento nada mais é que busca efetiva pela eficácia do sistema multiportas proposto pelas novas legislações, tais como Lei de Mediação e Código de Processo Civil que privilegiam a realização da mediação extrajudicial, evitando-se a intervenção da tutela Estatal na esfera privada. ${ }^{77}$

Aliás, o raciocínio da autora, assemelha-se com a filosofia do direito colaborativo, porquanto é um convite para as partes definirem por meio de cláusulas contratuais mecanismos, dentre eles a cláusula de mediação, para que assumam o protagonismo da resolução de conflitos que porventura venham surgir durante a relação jurídica contratual, do nascimento à extinção. ${ }^{78}$

Obviamente é imensamente vantajoso para as partes, seja pelo prisma econômico, temporal ou social, uma vez que não estarão sujeitos a um terceiro (juiz ou arbitro) para direcionarem a resolução do conflito por inexecução parcial ou total do contrato, a qual evidentemente já foi prevista antecipadamente pelas próprias partes. ${ }^{79}$

Impende inferir que direito colaborativo pode ser expandido no Direito brasileiro seja pela mediação ou arbitragem, principalmente, mas também se mostra por meio de convenções processuais de maneira eficaz, na medida em que impõe às partes soluções extrajudiciais vinculantes.

76 VASCONCELOS, Fernanda H.. Advocacia negocial: promoção do acesso à justiça pela desjudicialização dos conflitos. Editora A União. João Pessoa, 2014, p. 219-232.

77 DA SILVA, Vivien Lys Porto Ferreira. A Aderência da Cláusula de Mediação nos Contratos sob a Ótica dos Princípios Contratuais - Efetividade Privada versus Judicialização. Revista de Arbitragem e Mediação - RAM. v.12, n.46, jul. - set. 2015, pp. 173-195.

78 DA SILVA, Vivien Lys Porto Ferreira. A Aderência da Cláusula de Mediação nos Contratos sob a Ótica dos Princípios Contratuais - Efetividade Privada versus Judicialização.

79 DA SILVA, Vivien Lys Porto Ferreira. A Aderência da Cláusula de Mediação nos Contratos sob a Ótica dos Princípios Contratuais - Efetividade Privada versus Judicialização. 
RIBEIRO, Fabiano Colusso; HÜLSE, Levi. Direito colaborativo - um novo olhar sobre a resolução de conflitos. Revista Eletrônica Direito e Política, Programa de Pós-Graduação Stricto Sensu em Ciência Jurídica da UNIVALI, Itajaí, v.13, n.3, 30 quadrimestre de 2018. Disponível em: www.univali.br/direitoepolitica - ISSN 1980-7791

\section{CONSIDERAÇÕES FINAIS}

Diante do contexto atual, verifica-se direito colaborativo é um meio alternativo de resolução de conflitos, voluntário e contratual, desenvolvido e implantado por aproximadamente 25 (vinte e cinco) anos com grande êxito nos Estados Unidos, bem como no Canadá.

Este procedimento ou método é baseado essencialmente nas partes, em sua boa-fé, assistidas por seus respectivos advogados colaborativos e com a intervenção da equipe multidisciplinar adequada às circunstâncias. O procedimento fica regido pelo acordo de participação subscrito pelos participantes e sob a premissa de confidencialidade de todas as manifestações que são realizadas nela, bem como na condição de que entre os participantes que todo a informação relacionada com a controvérsia será compartilhada, caso contrário, acarretará a dissolução do acordo.

Do mesmo modo, ao finalizar o processo, nenhum dos advogados colaborativos poderá defender as partes em um processo judicial subsequente ou até mesmo consultoria em relação ao colaborativo.

O Direito Colaborativa consiste um novo serviço que pode oferecer aos clientes quando eles vão para escritórios de advocacia para obter consultoria ou aconselhamento, com o objetivo de oferecer a cada cliente o máximo de serviços integrados possíveis dentro do mesmo escritório, para que, advogado, pode analisar, avaliar e decidir qual sistema de resolução de conflitos é mais adequada às suas circunstâncias e necessidades. As práticas colaborativas permitem agregar técnicas de negociação e mediação no seu procedimento.

Na Brasil, não há nenhum tipo de regulamentação ou legislação a este respeito, o que, até o momento, a ordem jurídica não foi acionada para que regulamente este nova instituto, embora, como se viu, o Direito Colaborativo é perfeitamente compatível com o sistema jurídico brasileiro, sem necessidade de qualquer alteração legislativa, embora a sua regulamentação legislativa possa ajudar a disseminar e padronizar as práticas colaborativas.

O Direito Colaborativo nasceu nos Estados Unidos ligado ao Direito da Família, e aqui no Brasil também, e, portanto, a maioria das bibliografias existentes sobre o tema 
RIBEIRO, Fabiano Colusso; HÜLSE, Levi. Direito colaborativo - um novo olhar sobre a resolução de conflitos. Revista Eletrônica Direito e Política, Programa de Pós-Graduação Stricto Sensu em Ciência Jurídica da UNIVALI, Itajaí, v.13, n.3, $3^{\circ}$ quadrimestre de 2018. Disponível em: www.univali.br/direitoepolitica - ISSN 1980-7791

estão confinadas a essa área, daí a necessidade de aprofundamento do estudo do assunto em nosso país.

Portanto, devemos enfatizar que o Direito Colaborativo, por sua sistemática, possui um grande potencial para ser oferecido como serviço jurídico, não só ao nível do direito da família, mas também nos conflitos corporativos, trabalhistas, setor de saúde, etc.; porquanto permite que as partes detenham o controle do procedimento, mantendo-se todas as negociações confidenciais e livres da exposição pública, inerentes ao processo judicial.

\section{REFERÊNCIAS BIBLIOGRÁFICAS}

ALMEIDA, Gregório Assagra de. O Sistema Jurídico nos Estados Unidos. Revista de Processo. Editora Revista dos Tribunais. v. 41, n. 251, jan., 2016.

BARBOSA MOREIRA, José Carlos. O futuro da justiça: alguns mitos. Revista de Processo, v. 102, abr./jun. 2001, pp. 228-238.

BESSO, Chiara. La Mediazione Italiana: Definizioni e Tipologie. Revista Eletrônica de Direito Processual, Rio de Janeiro, v.6, n.4, p. 248-269, jul./dez. 2010. Disponível em: < http://www.arcos.org.br/periodicos/revista-eletronica-de-direitoprocessual/volume-vi/la-mediazione-italiana-definizioni-e-tipologie>. Acesso em: 25 jan. 2018. p. 33.

BOWE, Guy. Skills and Values: Alternative Dispute Resolution: Negotiation, Mediation, Collaborative Law, and Arbitration. Arbitration Law Review. Yearbook on Arbitration and Mediation. v. 6, Article 27, 2014.

BRASIL. Conselho Nacional de Justiça. LEI No 13.140, DE 26 DE JUNHO DE 2015. Disponível em: <http://www.planalto.gov.br/ccivil_03/_ato20152018/2015/Lei/L13140.htm >. Acesso em: 10.fev.2017.

BRASIL. Conselho Nacional de Justiça. Resolução no 125, de 29 de novembro de 2010. Dispõe sobre a Política Judiciária Nacional de tratamento adequado dos conflitos de interesses no âmbito do Poder Judiciário e dá outras providências. Disponível em: <http://www.cnj.jus.br/busca-atos-adm?documento=2579>. Acesso em: 01.fev.2017.

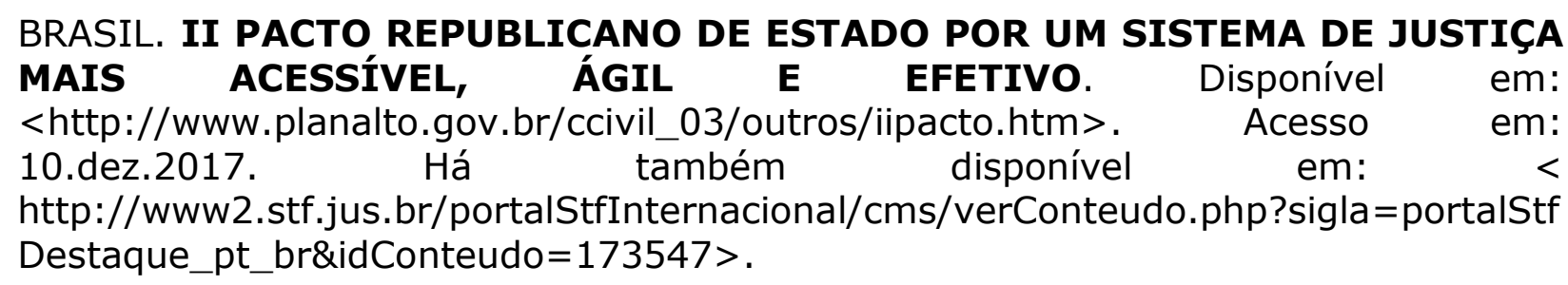


RIBEIRO, Fabiano Colusso; HÜLSE, Levi. Direito colaborativo - um novo olhar sobre a resolução de conflitos. Revista Eletrônica Direito e Política, Programa de Pós-Graduação Stricto Sensu em Ciência Jurídica da UNIVALI, Itajaí, v.13, n.3, 30 quadrimestre de 2018. Disponível em: www.univali.br/direitoepolitica - ISSN 1980-7791

BRASIL. Ministério da Justiça. Exposição de motivos ao anteprojeto de Lei de Mediação. Brasília: Congresso Nacional, 2013. Disponível em: <http://www.euroarbitragem.com.br/pt/anexo/Anteprojeto\%20-

\%20Lei\%20de\%20Media\%C3\%A7\%C3\%A30\%20(Comiss\%C3\%A30\%20M])\%20[E xp.\%20Motivos].pdf>. Acesso em: 29.jul.2016.

CABRAL, Antônio do passo; CUNHA, Leonardo Carneiro da. Negociação Direta ou resolução colaborativa de disputas (Collaborative Law): "mediação sem mediador". In: Justiça Multiportas: mediação, conciliação, arbitragem e outros meios de solução adequada para conflitos. Ed. Juspodvim, Salvador, 2016.

CALMON, Petronio. Fundamentos da mediação e da conciliação. 2.ed. Brasília, DF: Gazeta Jurídica, 2013. p. 135.

CHMATALIK, Cristiane Conde. JUNIOR, Américo Bedê. Conciliação - As Técnicas de Negociação e a Nova Política Judiciária instituída pelo novo CPC na Justiça Federal. In: Justiça Multiportas: mediação, conciliação, arbitragem e outros meios de solução adequada para conflitos. Ed. Juspodvim, Salvador, 2016, pp. 434436.

CHRISMAN, Oswin P., COX, Gay G., NOVOTNA, Petra Novotna. Collaborative Practice Mediation: Are We Ready to Serve this Emerging Market. Pepperdine Dispute Resolution Law Journal n. 6, Iss. 3, 2006, Disponível em: <http://digitalcommons.pepperdine.edu/drlj/vol6/iss3/4>. Acesso em: 22.dez.2017.

CRAWFORD, SANDRA. Collaborative Law: A Brief Overview. Illinois Bar Journal; Sep.2017, Vol. 105, Issue 9. Disponível em: < http://collablawil.org/wpcontent/uploads/2017/09/Collaborative-Overview.pdf>. Acesso em: 10.jan. 2018.

DA SILVA, Vivien Lys Porto Ferreira. A Aderência da Cláusula de Mediação nos Contratos sob a Ótica dos Princípios Contratuais - Efetividade Privada versus Judicialização. Revista de Arbitragem e Mediação - RAM. v.12, n.46, jul. - set. 2015.

DENARDI, Eveline Gonçalves; MOURA, Isabel Cristina de; FERNANDES, Mariana Correa. As práticas colaborativas como um recurso para as situações de divórcio. Revista da Faculdade de Direito da UFRGS, Porto Alegre, n. 36, vol. esp., p. 56-72, out. 2017.

DINAMARCO, Candido. Instituições de Direito Processual Civil. v.1. São Paulo, Malheiros.

ESTEVE, Patricia E. Abogado colaborativo: una nueva forma de resolución de conflictos. Revista Jurídica da Catalunha, RJC, núm. 1-2016, págs. 71-95.

FALCÃO, Joaquim.; ARGUELHES, Diego W.; RECONDO, Felipe.; Onze supremos: o supremo em 2016. Belo Horizonte (MG), 2017.

FISHER, Roger; WILLIAN, Ury; PATTON, Bruce. Como Chegar ao sim: a negociação de acordos sem concessões. 2.ed. Rio de Janeiro: Imago, 1994. 
RIBEIRO, Fabiano Colusso; HÜLSE, Levi. Direito colaborativo - um novo olhar sobre a resolução de conflitos. Revista Eletrônica Direito e Política, Programa de Pós-Graduação Stricto Sensu em Ciência Jurídica da UNIVALI, Itajaí, v.13, n.3, 30 quadrimestre de 2018. Disponível em: www.univali.br/direitoepolitica - ISSN 1980-7791

GOUVEIA, Mariana F. Curso de resolução alternativa de litígios. 2.ed. Coimbra: Almedina, 2012.

HOFFMAN, David A. Colliding Worlds of Dispute Resolution: Towards a Unified Field Theory of ADR. Journal of Dispute Resolution, 2008. Disponível em : <https://scholarship.law.missouri.edu/jdr/vol2008/iss1/4>. Acesso em: 05.jan.2018.

HOFFMAN, David. TESLER, Pauline. Collaborative Law and the Use of Settlement Counsel. The Alternative Dispute Resolution Practice Guide. B. Roth, ed. 2002. Disponível em: <https://blc.law/wp-content/uploads/2016/12/2005-07collaborative-law-and-settlement-counsel-branchmainlanguagedefault.pdf $>$. Acesso em: 05.jan.2018.

IACP - International Academy of Collaborative Professionals. História do Direito Colaborativo. Disponível em: <https://www.collaborativepractice.com/public/about/about-iacp/history.aspx>. Acesso em: 13.jan.2018.

LEMOS, Luciano Braga; LEMOS, Rodrigo Braga. A arbitragem e o direito. Belo Horizonte: Mandamentos Editora, 2003.

LOREDO COLUNGA, M. El método colaborativo: nuevos horizontes en el marco de la autocomposición. Revista de Justicia Restaurativa, Violencia de Género, Justicia Restaurativa y Mediación. Editora Grupo Wolters Kluwer. n.2, 2011.

MARINONI, Luiz Guilherme. Et. al. Novo curso de direito processual civil: teoria do processo civil. v.1. 2ed. São Paulo, 2016.

MOORE, Cristopher W. O Processo de Mediação: estratégias práticas para a resolução de conflitos. Tradução de Magda França Lopes. Porto Alegre: Ed. Artmed. 1998.

MORAIS, José Luis Bolzan de; SPENGLER, Fabiana Marion. Mediação e Arbitragem: alternativas à Jurisdição. 3.ed. Porto Alegre: Livraria do Advogado, 2012.

NOHMI, Antônio Marcos. Arbitragem internacional: mecanismos de solução de conflitos entre estados. Editora Del Rey. Belo Horizonte, FCH-FUMEC, 2005.

ORDEM DOS ADVOGADOS DO BRASIL. Resolução no 02, de 19 de outubro de 2015. Aprova o Código de Ética e Disciplina da Ordem dos Advogados Brasileiros. Disponível em:< http://s.oab.org.br/PDF/CFOAB-CED.pdf>. Acesso em: 15.jan. 2018.

PEDROSO, João et al. Percursos da informalização e da desjudicialização por caminhos da reforma da administração da justiça (análise comparativa). Coimbra, Centro de Estudos Sociais, 2001. Disponível em: <http://www.ces.uc.pt/publicacoes/oficina/ficheiros/171.pdf>. Acesso em: 15.dez.2016. 
RIBEIRO, Fabiano Colusso; HÜLSE, Levi. Direito colaborativo - um novo olhar sobre a resolução de conflitos. Revista Eletrônica Direito e Política, Programa de Pós-Graduação Stricto Sensu em Ciência Jurídica da UNIVALI, Itajaí, v.13, n.3, 30 quadrimestre de 2018. Disponível em: www.univali.br/direitoepolitica - ISSN 1980-7791

ROCHA, José de Albuquerque. Lei da arbitragem. São Paulo: Atlas, 2008.

SANDER, Frank E. A.. Future of ADR - The Earl F. Nelson Memorial Lecture. Journal of Dispute Resolution. Article 5 . Ano 2000. Disponível em: <https://scholarship.law.missouri.edu/jdr/vol2000/iss1/5>. Acesso em: 20.jan.2018.

SANTOS, Boaventura de Sousa. Os tribunais nas sociedades contemporâneas. Revista brasileira de ciências sociais. v. 11, n. 30, ps. 29-62, fev. 1996.

SANTOS, Boaventura Souza. Para uma revolução democrática da justiça. São Paulo: Editora Cortez, 3 ed. rev. amp. , 2007.

SCOTT, Marilyn. Collaborative Law: Dispute Resolution Competencies for the 'New Advocacy'. QUT Law Review, v. 8, n. 1, june 2008. Disponível em: <https://Ir.law.qut.edu.au/article/view/107>. Acesso em: 23.dez. 2017.

SERPA, Maria Nazareth. Teoria e Prática da Mediação de Conflitos. Rio de Janeiro: Lumen Juris, 1999.

SIMMONS, Martha Emily. Increasing Innovation in Legal Process: The Contribution of Collaborative Law. PhD Theses. Paper 11, 2015.

SPAIN, Larry. Collaborative Law: A Critical Reflection on Whether a Collaborative Orientation Can Be Ethically Incorporated in the Practice of Law. Baylor Law Review, Vol. 56, No. 1, 2004. Disponível em: <https://ssrn.com/abstract=2134397>. Acesso em: 12.jan.2018.

TESLER, Pauline H.. Collaborative Family Law. Pepperdine Dispute Resolution Law Journal. L.J. Iss. 3, 2004, pp.. 317-318. Disponível em: <http://digitalcommons.pepperdine.edu/drlj/vol4/iss3/2>. Acesso em: 12.dez. 2018.

TESLER, Pauline H.. Collaborative Family Law. Pepperdine Dispute Resolution Law Journal. L.J. Iss. 3, 2004, p. 317-318. Disponível em: <http://digitalcommons.pepperdine.edu/drlj/vol4/iss3/2>. Acesso em: 12.dez.2017.

THEODORO Júnior, Humberto Junior. Novo CPC - Fundamentos e sistematização - Humberto Theodoro Júnior, Dierle Nunes, Alexandre Melo Franco Bahia, Flávio Quinaud Pedron - Rio de Janeiro: Forense, 2015.

THEODORO Júnior, Humberto Junior. Novo CPC - Fundamentos e sistematização - Humberto Theodoro Júnior, Dierle Nunes, Alexandre Melo Franco Bahia, Flávio Quinaud Pedron - Rio de Janeiro: Forense, 2015.

VASCONCELOS, Fernanda H.. Advocacia negocial: promoção do acesso à justiça pela desjudicialização dos conflitos. Editora A União. João Pessoa, 2014. 
RIBEIRO, Fabiano Colusso; HÜLSE, Levi. Direito colaborativo - um novo olhar sobre a resolução de conflitos. Revista Eletrônica Direito e Política, Programa de Pós-Graduação Stricto Sensu em Ciência Jurídica da UNIVALI, Itajaí, v.13, n.3, 30 quadrimestre de 2018. Disponível em: www.univali.br/direitoepolitica - ISSN 1980-7791

VOEGELE, Gary L.; OUSKY, Ronald D. ; and WRAY, Linda K.. Collaborative Law: A Useful Tool for the Family Law Practitioner to Promote Better Outcomes. William Mitchell Law Review, 2007, Vol. 33: Iss. 3, Article 10, Disponível em: <http://open.mitchellhamline.edu/wmlr/vol33/iss3/10>. Acesso em: 22.dez.2017.

WEBB, Stuart. G. OUSKY, Ronald D.. The collaborative way to divorce: the revolutionary method that results in less stress, lower costs, and happier kids without going to court. Editora Plume, $1^{\text {a }}$ ed., Estados Unidos, 2007.

ZAJDSNAJDER, Luciano. Teoria e Prática da Negociação. Rio de Janeiro: José Olympio, 1985.

Recebido em: 23/04/2018

Aprovado em: 26/05/2018 